\title{
Impact of an AMOC weakening on the stability of the southern Amazon rainforest
}

\author{
Catrin Ciemer ${ }^{1,2, a}$, Ricarda Winkelmann ${ }^{1,3}$, Jürgen Kurths ${ }^{1,2,4,5}$, and Niklas Boers ${ }^{1,6,7}$ \\ 1 Potsdam Institute for Climate Impact Research, PO Box 601203, 14412 Potsdam, Germany \\ 2 Department of Physics, Humboldt University, Berlin, Germany \\ 3 Department of Physics and Astronomy, University of Potsdam, Potsdam, Germany \\ 4 Nizhny Novgorod State University, Nizhny Novgorod, Russia \\ ${ }^{5}$ Institute for Complex Systems and Mathematical Biology, University of Aberdeen, Aberdeen, UK \\ 6 Department of Mathematics and Computer Science, Free University of Berlin, Berlin, Germany \\ 7 Department of Mathematics and Global Systems Institute, University of Exeter, Devon, UK
}

Received 14 November 2020 / Accepted 26 May 2021 / Published online 28 June 2021 (C) The Author(s) 2021

\begin{abstract}
The Atlantic Meridional Overturning Circulation (AMOC) and the Amazon rainforest are potential tipping elements of the Earth system, i.e., they may respond with abrupt and potentially irreversible state transitions to a gradual change in forcing once a critical forcing threshold is crossed. With progressing global warming, it becomes more likely that the Amazon will reach such a critical threshold, due to projected reductions of precipitation in tropical South America, which would in turn trigger vegetation transitions from tropical forest to savanna. At the same time, global warming has likely already contributed to a weakening of the AMOC, which induces changes in tropical Atlantic sea-surface temperature (SST) patterns that in turn affect rainfall patterns in the Amazon. A large-scale decline or even dieback of the Amazon rainforest would imply the loss of the largest terrestrial carbon sink, and thereby have drastic consequences for the global climate. Here, we assess the direct impact of greenhouse gas-driven warming of the tropical Atlantic ocean on Amazon rainfall. In addition, we estimate the effect of an AMOC slowdown or collapse, e. g. induced by freshwater flux into the North Atlantic due to melting of the Greenland Ice Sheet, on Amazon rainfall. In order to provide a clear explanation of the underlying dynamics, we use a simple, but robust mathematical approach (based on the classical Stommel two-box model), ensuring consistency with a comprehensive general circulation model (HadGEM3). We find that these two processes, both caused by global warming, are likely to have competing impacts on the rainfall sum in the Amazon, and hence on the stability of the Amazon rainforest. A future AMOC decline may thus counteract direct global-warming-induced rainfall reductions. Tipping of the AMOC from the strong to the weak mode may therefore have a stabilizing effect on the Amazon rainforest.
\end{abstract}

\section{Introduction}

The anthropogenic release of greenhouse gases has lead to an increase in global mean temperatures (GMT) by more than $1.2^{\circ} \mathrm{C}$ above pre-industrial levels [1]. Although the Earth has experienced warmer periods in the long-term past, the recent GMT increase is unprecedented in magnitude and speed [2]. The rapid GMT increase might have drastic consequences for the Earth's climate and ecosystems, especially with regard to so-called "tipping elements" [3-5]. These subsystems, which include among others the AMOC, the polar ice sheets, the tropical monsoon systems as well as the Amazon rainforest, have the potential to undergo abrupt state transitions once a critical warming threshold is exceeded. Substantial progress has been made in

\footnotetext{
a e-mail: catrin.ciemer@pik-potsdam.de (corresponding author)
}

understanding these tipping elements and their respective dynamics. However, quantifying the associated critical thresholds has remained challenging. Partly, this is due to the fact that potentially highly nonlinear interactions between tipping elements, as well as their effect on the overall stability of the climate system, are still poorly understood. Interactions between different tipping elements may have a stabilizing effect, but could also lead to positive feedbacks in the climate system, and thus ultimately, to tipping cascades $[6,7]$.

In this publication, we consider two potential climatic tipping elements with a focus on their interaction: the AMOC, and the Amazon rainforest. In particular, we investigate how a weakening of the AMOC could, in the long-term, influence the Amazon rainforest via changes in tropical sea surface temperature (SST) patterns and associated rainfall changes in tropical South America. 
Substantial changes have recently been observed both for the Atlantic ocean circulation as well as the Amazon rainforest, mainly driven by anthropogenic climate change as well as effects from progressing deforestation: The AMOC has weakened by about $15 \%$ since the mid-twentieth century [8], which is at least partly due to enhanced freshwater flux into the North Atlantic from accelerated melting of the Greenland Ice Sheet [9] (for illustration see Fig. 1a). As a consequence of a slower transport of warm water masses from the tropics to the northern Atlantic due to a weakening of the AMOC, SST patterns around the globe are projected to change [10]. The SST patterns in the tropical Atlantic ocean and especially gradients between northern and southern tropical Atlantic SST anomalies in turn play an important role for rainfall in the Amazon basin, because of their impact on the latitudinal position of the Intertropical Convergence Zone (ITCZ) and hence on atmospheric moisture inflow from the Atlantic ocean to the South American tropics.

At the same time, simulations of comprehensive climate models suggest that a rising GMT has a decreasing effect on rainfall sums in the Amazon region [11]. In this context, the question arises whether a weakening or even shutdown of the AMOC would dampen or further enhance these projected rainfall reductions, and hence, how an AMOC collapse would influence the long-term stability of the Amazon rainforest [12].

\section{Data}

This study is based on observational data, as well as on simulations from the high-resolution general circulation model (GCM) HadGEM3 [10,13]. For the examination of correlations between annual tropical Atlantic SST anomalies and mean annual precipitation (MAP) in the southern Amazon, we employ observational data. The SSTs are taken from the Extended Reconstructed Sea Surface Temperature ERSST v3 data set [14] and MAP from the Global Precipitation Climatology Centre GPCC v7 [15]. Both data sets have a resolution of $2.5^{\circ} \times 2.5^{\circ}$ and are used for the time span 19212012. To examine the Amazon tree cover, we use the continuous tree cover distribution MOD44B at $500 \mathrm{~m}$ resolution for the year 2012 from the MODIS (Moderate Resolution Imaging Spectroradiometer/Terra vegetation continuous fields) data set [16]. We classify areas with tree cover percentages above $70 \%$ as forest. In order to guarantee an unbiased analysis, we neglect all human affected regions as defined by the IBGE data set [17]. This vegetation classification data set is only available for Brazil. We thus restrict our tree cover analysis to southern tropical Brazil $\left(5^{\circ} \mathrm{S}-15^{\circ} \mathrm{S}\right.$ and $42.5^{\circ} \mathrm{W}-$ $\left.75^{\circ} \mathrm{W}\right)$. The changes of SSTs due to an AMOC shutdown are estimated from a hosing experiment enforcing an AMOC shutdown using the Eddy-permitting HadGEM3 model [10,13,18].

\section{Methods}

\subsection{Influence of the AMOC strength on tropical Atlantic sea surface temperatures}

To model the relationship between the AMOC strength $\Psi$ (estimated in terms of North Atlantic deep water flow) and SST anomalies in the southern tropical Atlantic box, we use the heat-balance equations for the northern and tropical boxes of the well-established twobox Stommel model [19,20], and identify the tropical Stommel box with the southern tropical box as depicted in Fig. 1a. The latter choice is consistent with CMIP5 model simulations analyzing the impact of an AMOC collapse on SSTs [21]:

$$
\begin{aligned}
V_{p} \frac{\mathrm{d} T_{p}}{\mathrm{~d} t} & =C^{T}\left(T_{p}^{a}-T_{p}\right)+|\Psi|\left(T_{e}-T_{p}\right), \\
V_{e} \frac{\mathrm{d} T_{e}}{\mathrm{~d} t} & =C^{T}\left(T_{e}^{a}-T_{e}\right)+|\Psi|\left(T_{p}-T_{e}\right),
\end{aligned}
$$

where the subscript $p$ indicates parameters in the polar box and $e$ in the equator box, respectively. $V$ is the box volume, $T$ the temperature of the well-mixed box, and $C^{T}=3.17 \times 10^{6} \mathrm{~m}^{3} \mathrm{~s}^{-1}$ the relaxation coefficient that modulates the exchange of heat in each box due to the surface forcing [22]. The atmospheric temperature is indicated by $T^{a}$ and averaged over the corresponding box. The AMOC strength, $\Psi$, is a function of freshwater flux $f$ into the polar box. In order to calculate the changes in SSTs induced by an AMOC weakening, we assume the system to be in equilibrium (i.e., $\frac{d T_{p}}{d t}=\frac{d T_{e}}{d t}=0$ ). Solving this equation system for $T_{e}$ yields

$$
T_{e}(\Psi(f))=\frac{T_{e}^{a} \times C^{T}|\Psi(f)|\left(T_{p}^{a}+T_{e}^{a}\right)}{C^{T}+2|\Psi(f)|}
$$

The temperature change is thus $\Delta T_{e}(f)=T_{e}(f)-$ $T_{e}\left(f_{0}\right)$, where $f_{0}=0.09$ is the present freshwater flux. The conceptual Stommel model yields a qualitative description of the AMOC response to a changing freshwater forcing [23]. However, it does not give SST values, but rather box temperatures for the polar $\left(T_{p}\right)$ and the equator $\left(T_{e}\right)$ boxes, which are averages over multiple ocean depth layers. To obtain realistic SST values for the southern tropical Atlantic box, we therefore re-scale the box SSTs after an AMOC shutdown such that our results for $T_{e}$ are quantitatively reconciled with existing GCM results on southern tropical Atlantic SSTs, obtained from a simulated, hosinginduced AMOC shutdown. This yields a maximum SST change of $2.0^{\circ} \mathrm{C}$ in the southern tropical Atlantic ocean box $[10,13]$. With a weakening AMOC, sea-surface temperatures south of the equator are projected to increase, while they are expected to decrease north of the equator. We therefore defined the Stommel equator box to be located south of the equator and additionally determined a second ocean box north of the equator to dis- 

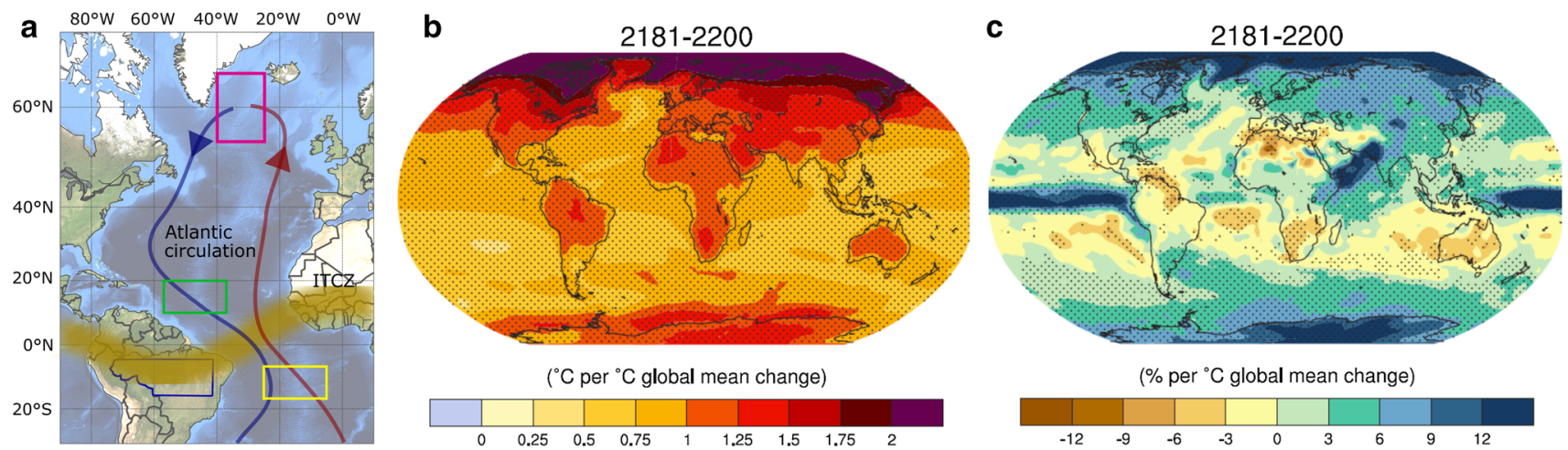

Fig. 1 Interactions between the AMOC and the Amazon rainforest. a Geographical location of the study areas (highlighted boxes). The northern polar box close to the coast of Greenland is marked in pink, the two tropical Atlantic boxes, which determine rainfall amounts in the southern Amazon, are shown in green (northern tropical) and yellow (southern tropical), respectively. The southern Amazon study region is marked in blue. The three Atlantic boxes are of the same size. The two equator boxes have been selected based on correlations between precipitation in the south-

ern Amazon box and Atlantic SSTs (Fig. 3a). Additionally, the AMOC and the ITCZ are illustrated schematically. $\mathbf{b}$ Surface air temperature (SAT) and c mean annual precipitation (MAP) changes projected for the years $2181-2200$ as derived from transient simulations from the CMIP5 ensembles [11]. The SAT and MAP changes are scaled to $1^{\circ} \mathrm{C}$ (see panel legend). The stippling illustrates where the mean change averaged over all realizations is larger than the $95 \%$ percentile of the distribution of the models. $\mathbf{b}$ and $\mathbf{c}$ are taken from [11], p. 1061
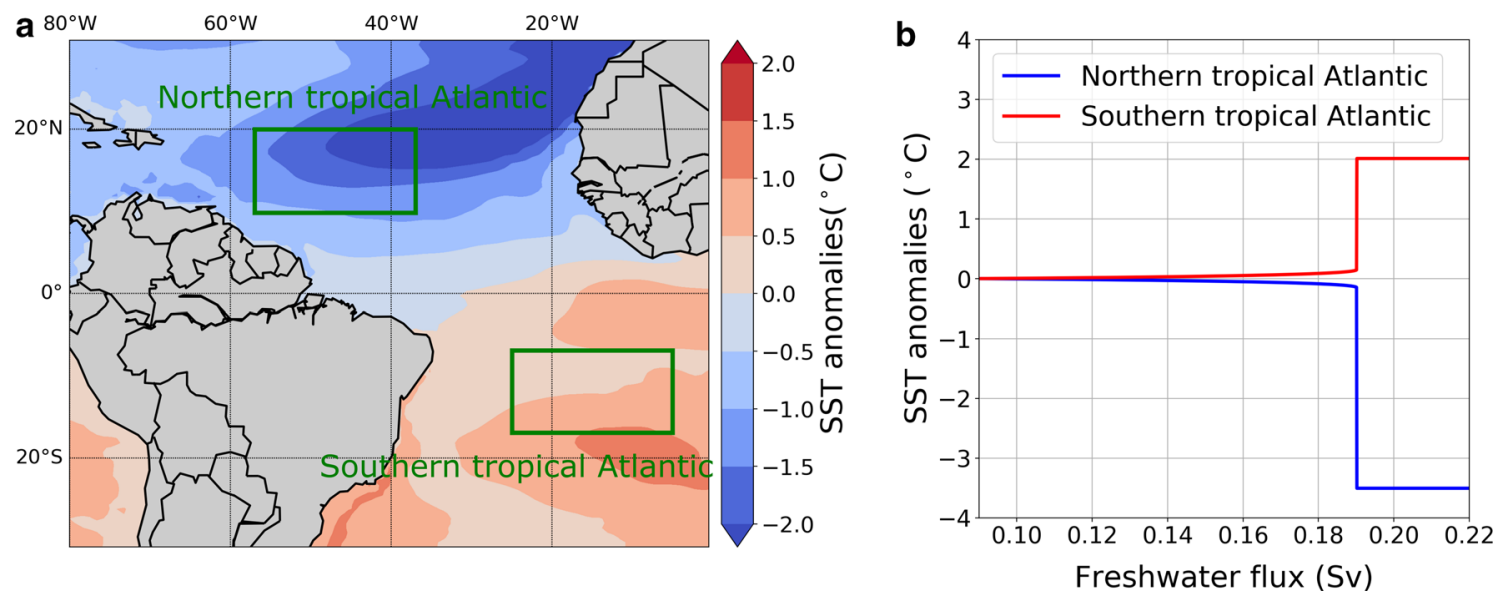

Fig. 2 Sea surface temperature (SST) anomalies due to an AMOC shutdown. a Spatial distribution of the SST anomalies taken from [13]. The green boxes indicate the areas of highest correlations to the southern Amazon as illustrated

tinguish these changes. The northern tropical Atlantic box SST anomalies associated with an AMOC shutdown are set to $-3.5^{\circ} \mathrm{C}$ in accordance with [13] (see Fig. 2a below for the projected spatial SST anomaly distribution after an AMOC shutdown, and for the specific choice of the two tropical boxes north and south of the equator).

\subsection{Estimating the influence of sea surface temperatures changes on mean annual precipitation}

Mean annual precipitation in the southern Amazon is strongly influenced by the gradient between the northern and southern tropical Atlantic ocean [24-26]. We determine the specific locations of oceanic regions with

in Fig. 3a. b SST anomalies averaged for the northern and southern tropical Atlantic box as indicated in a in dependence on the freshwater flux

highest impact on precipitation in the Amazon by calculating the Pearson's correlation coefficient between each SST grid cell, and precipitation averaged over the southern Amazon box. The spatial distribution of correlation coefficients is illustrated in Fig. 3a. We select the two areas with strongest positive and negative correlations, respectively, for further analysis. One is located north and one south of the equator. The spatially averaged SSTs in these two boxes are taken as input for a linear regression of precipitation in the southern Amazon on the two SST time series (Fig. 3b). This gives the following relation:

$$
\begin{aligned}
& \mathrm{MAP}=3590.4 \mathrm{~mm} / \mathrm{yr}-162.1 \frac{\mathrm{mm} / \mathrm{yr}}{{ }^{\circ} \mathrm{C}} \\
& \times \mathrm{SST}_{\text {north }}+116.0 \frac{\mathrm{mm} / \mathrm{yr}}{{ }^{\circ} \mathrm{C}} \times \mathrm{SST}_{\text {south }},
\end{aligned}
$$




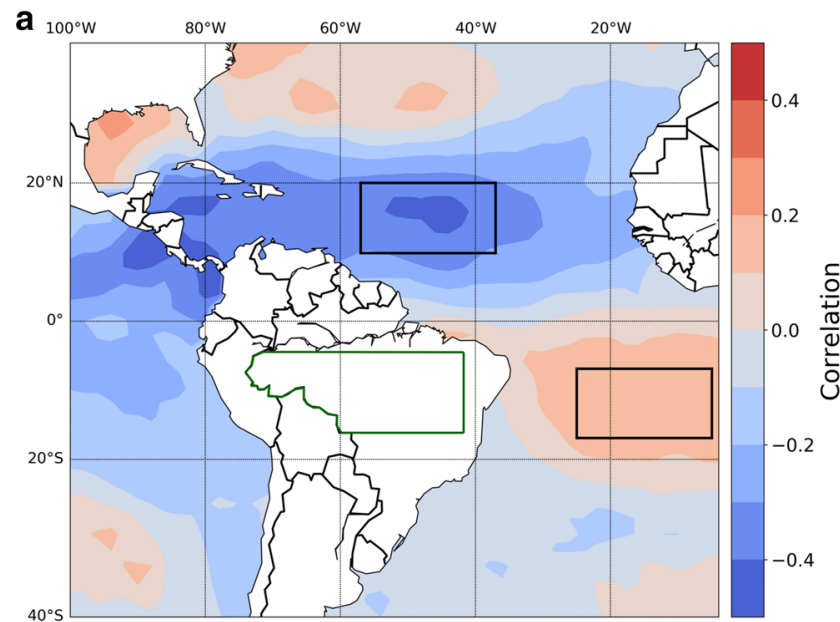

Fig. 3 Correlation of MAP and SSTs. a Pearson's correlation for annual SST and the MAP averaged over the southern Amazon (green box). The Atlantic ocean exhibits one highly negatively and one highly positively correlated region (black boxes). b Linear regression of southern Ama-

with a coefficient of determination of $R^{2}=0.254$. Global warming will additionally affect the SSTs/SATs and thus the MAP. As the expected temperature change is relatively homogenous across the tropical Atlantic ocean (see e. g. Fig. 1) and with this model focused on studying possible feedback loops, we incorporate the effect of global warming as a fixed amount in both boxes equally.

\subsection{Dependency of tree cover on mean annual precipitation}

The tree cover fraction in the Amazon rainforest depends primarily on the MAP $[12,27]$. We can associate stable and unstable states of vegetation with specific combinations of tree cover and MAP. For the tropical region under study, we link high tree cover $(\approx 80 \%)$ to rainforest and low tree cover $(\approx 15 \%)$ to savanna as shown in Fig. 4a. To quantify the probability of an area to be in the forest state, we first estimate the probability density function of the tree cover distribution for a fixed range of MAP with a Gaussian kernel density estimation (KDE). For the selection of the band width, the Silverman method is applied, that is

$$
\text { band width }={\frac{n(d+2)^{-\frac{1}{d+4}}}{4}}
$$

with the number of data points $n$ and dimension $d=1$. We use a sliding window approach with a MAP window size of $200 \mathrm{~mm} / \mathrm{yr}$ to guarantee a sufficient amount of data points in each window. The minimum of each KDE is taken as the boundary between forest and savanna (see Fig. 4b, c). To quantify the probability of a region to be in the forest state, we integrate the corresponding KDE-estimated probability density function from

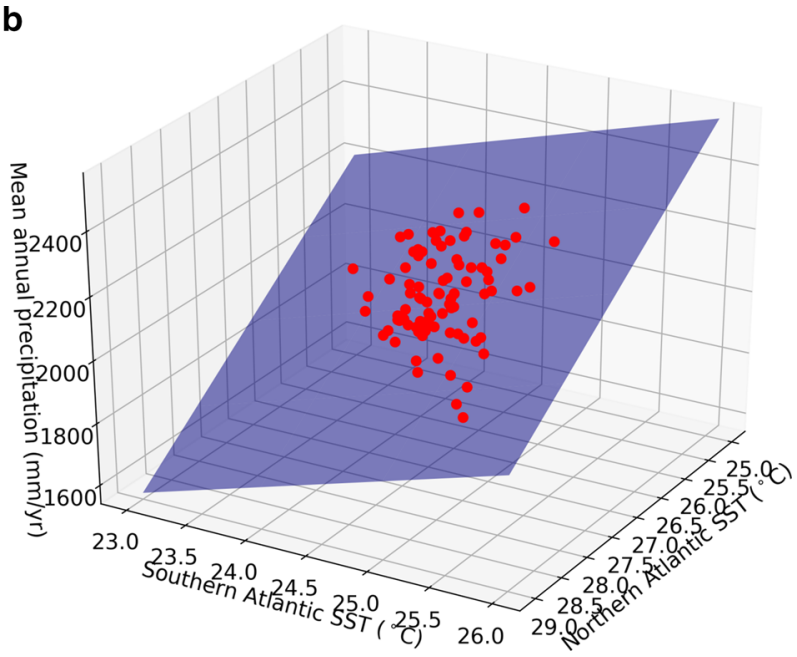

zon MAP onto SST anomalies of the two tropical Atlantic boxes, as indicated in $\mathbf{a}$. The red dots illustrate the fitted data points, and the blue plane the bivariate regression. The SSTs as well as the MAP are averaged over the entire boxes for every time step

this boundary to the maximum tree cover of $100 \%$. This probability is plotted as a function of the MAP in Fig. 5c and, for projected changes in GMT and North Atlantic freshwater flux, in Fig. 6b. Above a MAP of $2100 \mathrm{~mm} / \mathrm{yr}$, exclusively rainforest can be sustained. Below this amount of MAP, rainforest and savanna can both exist, defining a MAP range for which the vegetation is bi-stable. If the MAP falls below an amount of $1700 \mathrm{~mm} / \mathrm{yr}$, the probability to find a rainforest is beneath $50 \%$. In case of MAP below $1300 \mathrm{~mm} / \mathrm{yr}$, rainforest is virtually non-existent.

\section{Results}

In the following, we study the combined impact of an AMOC shutdown and global warming on the Amazon rainforest. We first investigate the correlations between Atlantic SSTs and MAP in the southern Amazon. For the investigation of the interaction of the two tipping elements, we assess how a slowing down of the AMOC would affect the precipitation in the Amazon basin. In a second step, we take the direct influence of global warming on tropical Atlantic SSTs into account. Finally, we combine both effects and study their competing impacts on the southern Amazon rainforest.

\subsection{Impact of an AMOC collapse}

As a first step, we examine the effect of increased freshwater flux, which we assume to be dominated by Greenland melt water runoff, on the AMOC strength. To this end, we use the simple two-box model [19] introduced above. Based on this model, we estimate a flow rate of approximately $16 \mathrm{~Sv}$ at present. The dynamical sys- 
a

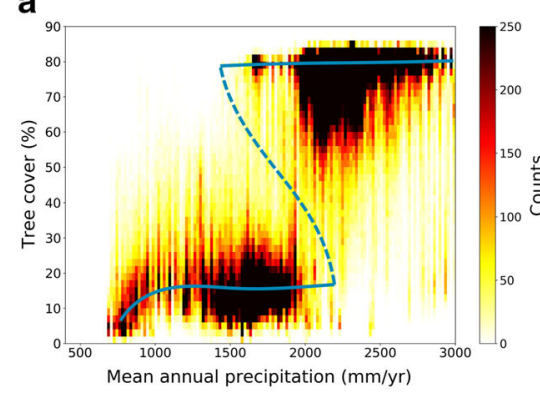

b

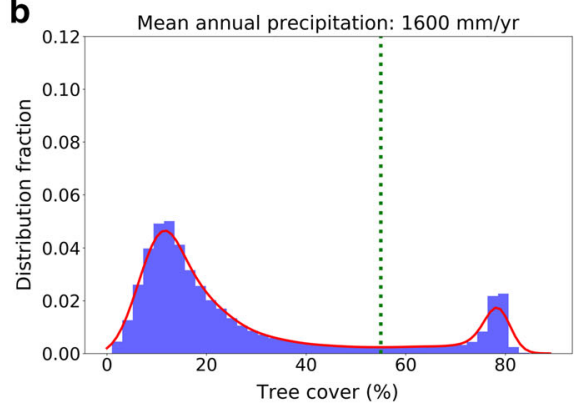

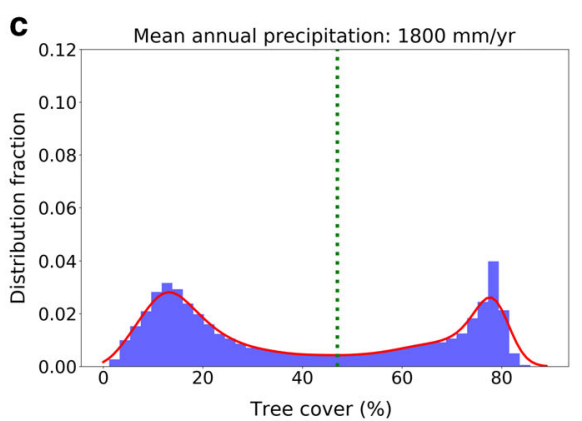

Fig. 4 Tree cover fraction in dependence on mean annual precipitation. a Distribution of tree cover in the Amazon in dependence of MAP. The color strength indicates the frequency of occurrence. The blue solid line indicates MAP ranges where a forest state (upper line) and a savanna state (lower line), respectively, are sustainable. b, c Distribution of tree cover for fixed amounts of MAP. The red solid line illustrates the KDE fit of the data and the green dashed line the local minimum of the distribution, as separation between the savanna and forest states tem for the AMOC strength as a function of freshwater influx exhibits a bifurcation at a critical threshold for the freshwater influx (Fig. 5a) [23]. Excessive melting of the Greenland ice sheet and the resulting additional freshwater flow lead a shutdown of the AMOC after crossing the bifurcation point. In accordance with the bifurcation diagram and the associated hysteresis, the freshwater flux would have to be reduced much beyond present-day levels to bring the AMOC back to its current state.

Figure 2 illustrates the SST anomalies caused by a shutdown of the AMOC, as estimated in [13]. SSTs in the tropical Atlantic ocean north of the equator are projected to become colder, while SSTs in the tropical Atlantic ocean south of the equator will become warmer which is consistent with a diminished northward heat transport by the AMOC. Currently, tropical Atlantic ocean SSTs are changing slowly. Once the AMOC tipping point is crossed, however, they are predicted to change abruptly.

Due to the projected SST changes associated with an AMOC collapse, the ITCZ is expected to shift southward (Fig. 2b) and consequently, the MAP in the southern Amazon will rise (Fig. 5b). Therefore, at least the southern Amazon rainforest will, in fact, become more stable due to an AMOC shutdown (Fig. 5c).

\subsection{Impact of global warming on the Amazon rainforest}

In our conceptual approach, we assume that with global warming, the surface air temperature (SAT) above both Atlantic boxes is rising equally. This would lead to a decrease of the MAP in the southern Amazon as shown in Fig. 6a. At present, the MAP is estimated at $2100 \mathrm{~mm} / \mathrm{yr}$ using the approach described above. We find that the already observed GMT rise of roughly $1^{\circ} \mathrm{C}$ compared to pre-industrial levels would cause a reduction of $100 \mathrm{~mm} / \mathrm{yr}$ in MAP.

\subsection{Influences of an increasing freshwater flux and global warming on the Amazon rainforest}

Finally, we combine the rather simple approaches introduced above to study the long-term influence of increased North Atlantic freshwater flux and global warming on the stability of the Amazon rainforest. Figure $6 \mathrm{~b}$ shows the probability for the rainforest to be sustained in dependence on both increasing freshwater flux into the North Atlantic, and rising SATs in the tropical Atlantic due to global warming. We find that an increase in freshwater flux causes reductions of AMOC strength and associated changes in tropical Atlantic SSTs, to enhance the MAP in the southern Amazon. This, in turn, leads to MAP values which would favor the rainforest state over the savanna state. As stated before, global warming, on the other hand, decreases MAP and thus contributes to a destabilization of the forest.

\section{Discussion}

\subsection{Influence of tropical Atlantic SSTs on mean annual precipitation in the southern Amazon}

Concerning the long-term correlations between Atlantic SSTs and MAP in the southern Amazon, we uncover a northern tropical Atlantic ocean region for which SST anomalies are negatively correlated with MAP in the Amazon, and a southern tropical Atlantic ocean region with positive correlations between SST anomalies and Amazon MAP (Fig. 3). The SST gradient between these two tropical Atlantic regions affects the latitudinal position of the ITCZ and thereby influences moisture inflow and thus eventually rainfall amounts in tropical South America. A warmer (colder) northern tropical Atlantic and at the same time a colder (warmer) southern tropical Atlantic leads to a northward (southward) ITCZ shift and thus less (more) precipitation in the southern Amazon $[24,28]$. In accordance, a regression of south- 

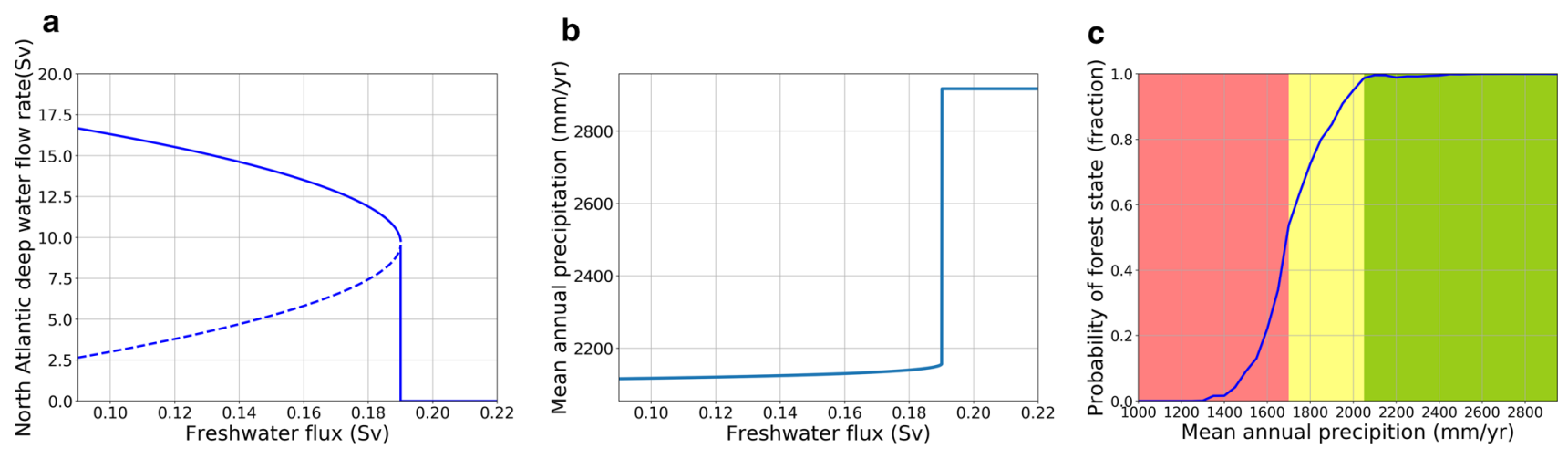

Fig. 5 Linking AMOC strength to rainforest stability. a North Atlantic deep water flow rate as a proxy for AMOC strength in dependence on the North Atlantic freshwater flux, dominated by Greenland ice sheet meltwater runoff, as calculated from the two-box Stommel model [19,23]. The current north Atlantic deep water flow rate is estimated at about $16 \mathrm{~Sv}$. b The MAP in dependence of the fresh-

a

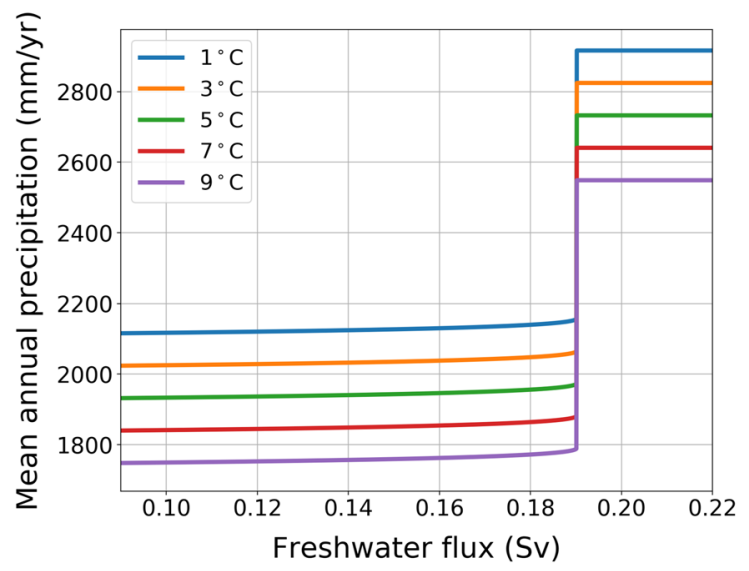

Fig. 6 Competing effects of global warming and a slowing down of the AMOC. a MAP in dependence on the freshwater flux (x-axis) and global warming (in colors). Presently, we assume a freshwater flux of $f=0.09 \mathrm{~Sv}$ [23] and a global warming level of $1^{\circ} \mathrm{C}$. With an increase of the freshwater flux

ern Amazon rainfall anomalies onto the annual SST anomalies of the two Atlantic boxes implies that SST changes due to an AMOC weakening would increase the MAP in the southern Amazon. The estimated amount of MAP increase in the southern Amazon due to an AMOC shutdown, as inferred here via the regression based on observed data, is in good agreement with corresponding model simulations $[29,30]$.

\subsection{Impact of an AMOC shutdown on the Amazon rainforest}

Our estimated response of the North Atlantic deep water flow rate - used here as a proxy for the AMOC strength - to increasing North Atlantic freshwater flux, based on the simple Stommel model (Fig. 5a), is in water flux. The MAP does initially not alter much due to an increase in the freshwater flux. Beyond the tipping of the AMOC, however, the MAP will increase rapidly to an amount of approximately $2900 \mathrm{~mm} / \mathrm{yr}$. c Probability of forest state with respect to the MAP in the southern Amazon region. The colors indicate probability ranges of $98 \%-100 \%$ in green, $50 \%-98 \%$ in yellow, and below $50 \%$ in red

\section{b}

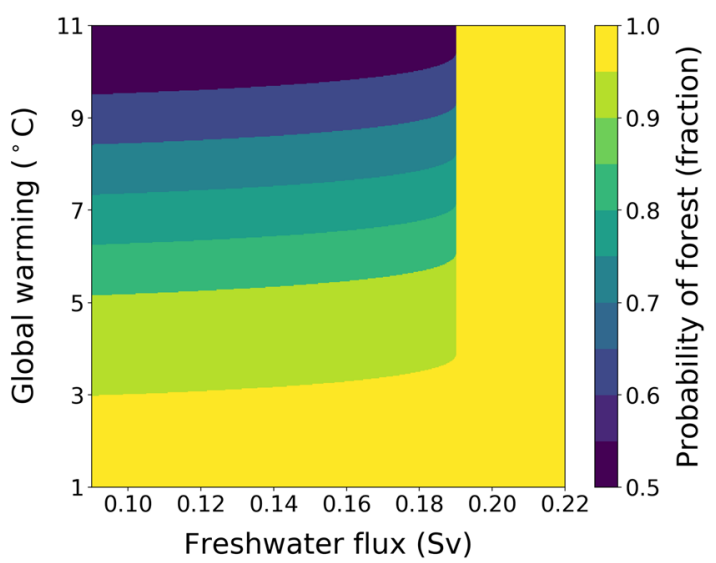

the MAP increases. In contrast, an increase in global warming leads to a decrease of MAP in the southern Amazon. b Phase-space diagram of freshwater flux and global warming and their influence on the probability of the southern Amazon rainforest to persist (in colors)

very good agreement with simulations of considerably more complex models [23]. For example, in the GCMbased hosing experiments by [21], an instant freshwater forcing of $0.1 \mathrm{~Sv}$ leads to a decrease of the AMOC strength of about 30\%, in accordance with Fig. 5a. Two other GCM-based hosing experiments, with freshwater fluxes of $1.0 \mathrm{~Sv}$ and $0.6 \mathrm{~Sv}$, respectively, lead to an AMOC breakdown $[29,30]$. As such, this simple but robust modelling approach is suitable for understanding how freshwater flux into the polar Atlantic Ocean may affect the AMOC and, as a result, the Amazon rainforest. While this approach has limits (especially assuming equilibrium and focusing on the direct interplay between freshwater flux, AMOC and precipitation), it demonstrates a powerful way to model the fundamental interactions of tipping elements. In order to investigate 
more specific questions, this model may be extended (e.g. by adding further granulatity to geographical temperature or precipitation distributions).

We adopt the SST changes caused by a hosinginduced shutdown of the AMOC from [10,13,18] (Fig. 2a). They are roughly in accordance with some previous simulations of an AMOC shutdown, e.g. [29,30], but should be considered substantially more reliable because the HadGEM3 model is more comprehensive than models previously used, and because the simulations are performed at considerably higher, Eddy-permitting resolution. Combining this projection of decreasing northern tropical Atlantic SSTs alongside increasing southern tropical Atlantic SSTs with our regression estimate between tropical Atlantic SSTs and MAP in the southern Amazon, we infer that the MAP will increase by approximately $800 \mathrm{~mm} / \mathrm{yr}$ due to a tipping of the AMOC (Fig. 5b). This will, in turn, favor the tropical forest state over the savanna state: At MAP above $2100 \mathrm{~mm} / \mathrm{yr}$, the rainforest state would be the only stable vegetation state (Fig. 5c). Additionally, it could lead to a spreading of the forest in areas which currently favor savanna vegetation. However, the correlation structure of tropical Atlantic SST to MAP anomalies is only true for the study area in the southern Amazon. In the northern Amazon for instance, MAP is projected to decrease as a consequence of an AMOC shutdown [13], in agreement with the induced southward shift of the ITCZ.

\subsection{Impact of global warming on the Amazon rainforest}

Compared to the impact of an AMOC slowdown, global warming has the opposite effect on MAP in the southern Amazon (Fig. 6a). In our simplified model, the SAT increases uniformly in both boxes. This leads to a decrease in MAP in the study area. The reduction of MAP due to changing tropical Atlantic SATs in our model is consistent with future IPCC projections (Fig. 1b, c) [31]. This indicates that the global warminginduced changes in tropical Atlantic SSTs are, according to the CMIP models, indeed the main driver of precipitation changes in the Amazon.

\subsection{Combined influence of $A M O C$ slowdown and global warming on the Amazon rainforest}

While the fresh water flow is expected to further increase in the future, due to further melting of the Greenland ice sheet as well as an overall acceleration of the hydrological cycle, GMTs will rise further as well. For freshwater flux values consistent with a strong AMOC state, we observe a critical temperature of global warming beyond which the probability, and hence also the stability, of the forest state decreases rapidly (Fig. 6b). For high values of global warming, any disturbance such as a forest fire or drought could lead to a dieback from which the rainforest might not be able to recover [26]. On the contrary, an AMOC weaken- ing or collapse, as expected for drastic global warming levels due to the melting of the Greenland ice sheet, would increase precipitation in the southern Amazon, and thus could cause a stabilization of the rainforest. Our analysis indicates that in case of a tipping of the AMOC, the MAP will increase to a level that even a global warming of $11^{\circ} \mathrm{C}$ cannot have a destabilizing impact on the tropical forest. For the highest representative concentration pathways 8.5, the IPCC predicts an increase of global SAT of $2-4^{\circ} \mathrm{C}$ by 2100 and $4-7^{\circ} \mathrm{C}$ by 2200 (Fig. 1b) [31]. In case that the SAT in the tropical Atlantic rises by more than $3^{\circ} \mathrm{C}$, our conceptional study estimates that the MAP will reduce below a point where the rainforest in the southern Amazon might transition to savanna due to an external disturbance. Thus, the tropical forest might be dependent on a slowing down of the AMOC in order to sustain. Therefore, the specific way in which the AMOC and the Amazon interact, reveals an example of a negative feedback between tipping elements, with stabilizing effects.

\section{Conclusion}

In this study, we get first insights into the long-term impacts of a slowdown of the AMOC on the Amazon rainforest. A shutdown of the AMOC impacts SSTs globally [13]. In the tropical Atlantic, the SSTs north of the equator decrease, while the SSTs south of the equator increase, consistent with weakening northward heat transport at the surface by the AMOC. This leads to a southward shift of the ITCZ and thus, to an increase in MAP in the southern Amazon. On the other hand, MAP has been projected to decrease in this region due to the direct effects of global warming, as shown in GCM simulations. In summary, this implies that global warming will lead to two competing effects concerning MAP in the southern Amazon: Indirectly, global warming will cause increased freshwater flux into the North Atlantic - dominantly via melting of the Greenland ice sheet - and is therefore likely to contribute to a weakening of the AMOC, and hence, to an increase in MAP in the southern Amazon. Directly, however, warming of tropical Atlantic SSTs is projected by GCMs to lead to decreases in MAP at the same time. Therefore, the actual temporal trajectories of the system in Fig. $6 \mathrm{~b}$ would start from the lower left and move towards the upper right. On the one hand, a rise in the global mean temperature reduces the probability of the forest to sustain due to a reduction of MAP. On the other hand, an increase in the freshwater flow causes intensification of the MAP and, therefore, increases the stability of the rainforest.

In our analysis, we investigate the combined effect of rising global mean temperatures and a possible AMOC collapse on rainfall sums in the Amazon basin. Yet, the AMOC slowdown and eventual collapse would also be caused by rising global mean temperatures; partly directly via thermal expansion of the water masses, partly indirectly via increased freshwater flux 
into the North Atlantic, e.g. from Greenland meltwater runoff. We note that the specific way in which we have addressed the combined effects is consistent with the fact that we analyze the ramification of one common cause (namely global warming), on the one hand directly, and on the other hand indirectly via its impact on the AMOC. In particular, it remains unclear how global warming will affect the AMOC in the coming decades to centuries, and our approach, as summarized in Fig 6, allows to take that uncertainty into account. Future research should also consider explicit causality measures [32].

Our results are, partly by construction, in accordance with the mentioned GCM studies [10,13,21,29,30], and moreover capture some of the qualitative changes suggested by paleo evidence: [33] for instance conclude that the South American monsoon has been stable for at least the past 94,000 years; the Amazon rainforest itself has likely persisted for at least 40 million years, and hence even longer than the Andes mountain range. The results of [33] and [34] also suggests that during the last glacial interval, abrupt changes of MAP in the Amazon occurred in synchrony with Greenland Dansgaard-Oeschger events, in accordance with corresponding changes in AMOC strength.

In our very simplified approach, we neglected potential future changes in the dependency structure between tropical Atlantic SSTs, atmospheric circulation and, hence, Amazon precipitation. As mentioned above, our results in this regard are, however, consistent with the current IPCC projections. We also acquire that the rainforest is only dependent on MAP. Of course, other parameters will have impacts on the vegetation state as well, as e.g., increased evapotranspiration or rising temperatures in the Amazon region as a consequence of global warming, as well as direct plantphysiological effects of rising atmospheric $\mathrm{CO}_{2}$ concentrations. These effects should be investigated with coupled, high-resolution models such as the one used in [10]

Our results show that a critical level of global warming exists, beyond which the Amazon vegetation may rapidly shift from the forest to a savanna state. This threshold should not be regarded quantitatively, since our conceptual study only assesses the impact of global warming via changes in tropical Atlantic SSTs, but neglects direct effects of air temperature and carbon dioxide concentrations on the functioning of the rainforest. Quantitative estimates for this threshold should be obtained in further research, with comprehensive high-resolution Earth System Models with dynamic atmosphere-vegetation coupling.

These first insights based on our conceptual approach underline the importance of improving our understanding of the interactions between different subsystems of the climate system, and in particular the importance of better quantifying feedbacks between the tipping elements in question, for the long-term stability of the Amazon rainforest. It should be of interest to further analyze these impacts in spatially explicit, coupled GCM simulations at Eddy-permitting resolution.
We further suggest that the two competing effects of global warming and changes in the AMOC strength on the fate of the Amazon rainforest need to be taken into account when assessing the future evolution of the tropical rainforest.

Acknowledgements We are grateful to Jonathan Donges for the valuable discussions. This paper was developed within the scope of the IRTG 1740/TRP 2011/501510, funded by the DFG/FAPESP. C.C. acknowledges support by the German Federal Ministry for Education and Research (BMBF) via the Young Investigators Group CoSy$\mathrm{CC}^{2}$ (grant no. 01LN1306A) and the Belmont Forum/JPI Climate project GOTHAM (grant no. 01LP1611A). J.K. acknowledges support by the grant of the Ministry of Education and Science of the Russian Federation Agreement No. 075-15-2020-808. N.B. acknowledges funding by the Volkswagen Foundation, the German Federal Ministry for Education and Research, and the German Science Foundation (DFG, Reference BO 4455/1-1). The present paper is TiPES contribution \# 100; the TiPES (Tipping Points in the Earth System) project has received funding from the European Union's Horizon 2020 research and innovation program under grant agreement No. 820970.

Funding Open Access funding enabled and organized by Projekt DEAL.

Data Availability Statement My manuscript has no associated data or the data will not be deposited.

\section{Declarations}

Conflict of interest The authors declare that they have no competing financial interests.

Open Access This article is licensed under a Creative Commons Attribution 4.0 International License, which permits use, sharing, adaptation, distribution and reproduction in any medium or format, as long as you give appropriate credit to the original author(s) and the source, provide a link to the Creative Commons licence, and indicate if changes were made. The images or other third party material in this article are included in the article's Creative Commons licence, unless indicated otherwise in a credit line to the material. If material is not included in the article's Creative Commons licence and your intended use is not permitted by statutory regulation or exceeds the permitted use, you will need to obtain permission directly from the copyright holder. To view a copy of this licence, visit http://creativecomm ons.org/licenses/by/4.0/.

\section{References}

1. I. Niang, et al. Climate change 2014: impacts, adaptation, and vulnerability. part b: regional aspects (2017)

2. S. Sippel, N. Meinshausen, E.M. Fischer, E. Székely, R. Knutti, Climate change now detectable from any single day of weather at global scale. Nat. Clim. Chang 10, 35-41 (2020) 
3. T.M. Lenton et al., Tipping elements in the earth's climate system. Proc. Natl. Acad. Sci. 105, 1786-1793 (2008)

4. E. Kriegler, J.W. Hall, H. Held, R. Dawson, H.J. Schellnhuber, Imprecise probability assessment of tipping points in the climate system. Proc. Natl. Acad. Sci. 106, 5041-5046 (2009)

5. H.J. Schellnhuber, S. Rahmstorf, R. Winkelmann, Why the right climate target was agreed in Paris. Nat. Clim. Chang 6, 649-653 (2016)

6. N. Wunderling, J.F. Donges, J. Kurths, R. Winkelmann, Interacting tipping elements increase risk of climate domino effects under global warming. Earth Syst. Dyn. Discuss. 1-21(2020)

7. T. M. Lenton et al. Climate tipping points-too risky to bet against (2019)

8. L. Caesar, S. Rahmstorf, A. Robinson, G. Feulner, V. Saba, Observed fingerprint of a weakening Atlantic Ocean overturning circulation. Nature 556, 191 (2018)

9. E. Rignot, I. Velicogna, M.R. van den Broeke, A. Monaghan, J.T. Lenaerts, Acceleration of the contribution of the Greenland and Antarctic ice sheets to sea level rise. Geophys. Res. Lett. 38(2011)

10. L. Jackson et al., Global and European climate impacts of a slowdown of the amoc in a high resolution $\mathrm{gcm}$. Clim. Dyn. 45, 3299-3316 (2015)

11. G. Myhre, et al. Climate change 2013: the physical science basis. Contribution of Working Group I to the Fifth Assessment Report of the Intergovernmental Panel on Climate Change. K., Tignor, M., Allen, SK, Boschung, J., Nauels, A., Xia, Y., Bex, V., and Midgley, PM, Cambridge University Press, Cambridge (2013)

12. C. Ciemer et al., Higher resilience to climatic disturbances in tropical vegetation exposed to more variable rainfall. Nat. Geosci. 12, 174-179 (2019)

13. M.S. Williamson et al., Effect of amoc collapse on enso in a high resolution general circulation model. Clim. Dyn. 50, 2537-2552 (2018)

14. T.M. Smith, R.W. Reynolds, T.C. Peterson, J. Lawrimore, Improvements to NOAA's historical merged land-ocean surface temperature analysis (1880-2006). J. Clim. 21, 2283-2296 (2008)

15. U. Schneider, et al., GPCC full data reanalysis version 6.0 at 0.5 : Monthly land-surface precipitation from raingauges built on GTS-based and historic data. GPCC Data Rep. 10(2011)

16. M. Hansen et al., Global percent tree cover at a spatial resolution of 500 meters: first results of the modis vegetation continuous fields algorithm. Earth Interact. 7, 1-15 (2003)

17. I. Brazil, Mapa de Vegetação do Brasil (2012)
18. J. Mecking, S. Drijfhout, L. Jackson, T. Graham, Stable amoc off state in an eddy-permitting coupled climate model. Clim. Dyn. 47, 2455-2470 (2016)

19. H. Stommel, Thermohaline convection with two stable regimes of flow. Tellus 13, 224-230 (1961)

20. H.A. Dijkstra, Nonlinear Climate Dynamics (Cambridge University Press, Cambridge, 2013)

21. A. Timmermann et al., The influence of a weakening of the Atlantic meridional overturning circulation on ENSO. J. Clim. 20, 4899-4919 (2007)

22. X. Wu, M. Mu, Impact of horizontal diffusion on the nonlinear stability of thermohaline circulation in a modified box model. J. Phys. Oceanogr. 39, 798-805 (2009)

23. S. Rahmstorf, On the freshwater forcing and transport of the Atlantic thermohaline circulation. Clim. Dyn. 12, 799-811 (1996)

24. P.M. Cox et al., Increasing risk of amazonian drought due to decreasing aerosol pollution. Nature 453, 212215 (2008)

25. J.-H. Yoon, Multi-model analysis of the Atlantic influence on Southern Amazon rainfall. Atmos. Sci. Lett. 17, 122-127 (2016)

26. C. Ciemer et al., An early-warning indicator for amazon droughts exclusively based on tropical atlantic sea surface temperatures. Environ. Res. Lett. 15, 094087 (2020)

27. M. Hirota, M. Holmgren, E.H. Van Nes, M. Scheffer, Global resilience of tropical forest and savanna to critical transitions. Science 334, 232-235 (2011)

28. J.-H. Yoon, N. Zeng, An Atlantic influence on Amazon rainfall. Clim. Dyn. 34, 249-264 (2010)

29. R. Zhang, T.L. Delworth, Simulated tropical response to a substantial weakening of the Atlantic thermohaline circulation. J. Clim. 18, 1853-1860 (2005)

30. R. Stouffer et al., Investigating the causes of the response of the thermohaline circulation to past and future climate changes. J. Clim. 19, 1365-1387 (2006)

31. V. Barros, et al., Climate change 2014: impacts, adaptation, and vulnerability-part b: regional aspectscontribution of working group ii to the fifth assessment report of the intergovernmental panel on climate change (2014)

32. J. Runge et al., Identifying causal gateways and mediators in complex spatio-temporal systems. Nat. Commun. 6, 1-10 (2015)

33. N.A.S. Mosblech et al., North Atlantic forcing of Amazonian precipitation during the last ice age. Nat. Geosci. 5, 817-820 (2012)

34. G. Deplazes et al., Links between tropical rainfall and North Atlantic climate during the last glacial period. Nat. Geosci. 6, 213-217 (2013) 